\title{
Preparation of Poly(7-formylindole)/carbon Fibers Nanocomposites and Their High Capacitance Behaviors
}

\author{
Guo Ye ${ }^{1, \S}$, Xiumei Ma ${ }^{2, \S}$, Yun $\mathrm{He}^{2}$, Xuemin Duan ${ }^{1}$, Weiqiang Zhou ${ }^{2, *}$, Jingkun $\mathrm{Xu}^{1, *}$ \\ ${ }^{1}$ School of Pharmacy, Jiangxi Science and Technology Normal University, Nanchang 330013, China \\ ${ }^{2}$ Jiangxi Engineering Laboratory of Waterborne Coatings, Jiangxi Science and Technology Normal \\ University, Nanchang 330013 \\ *E-mail: zhouwqh@163.com, xujingkun@jxstnu.edu.cn \\ ${ }^{\S}$ Guo Ye and Xiumei Ma, these authors contributed equally to this work.
}

doi: $10.20964 / 2017.09 .72$

Received: 16 May 2017 / Accepted: 25 July 2017 / Published: 13 August 2017

\begin{abstract}
Polyindoles belonging to the fused-ring family have attracted extensive investigation as promising materials due to their unique physical and electrochemical properties. Herein, poly(7-formylindole) (PFIn) film was firstly synthesized electrochemically on carbon fibers by direct anodic oxidation of 7-

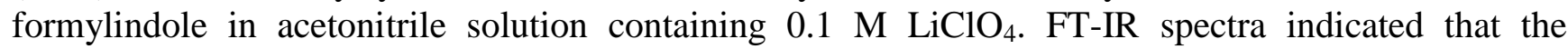
polymerization site of monomer happened at the $\mathrm{C}_{2}$ and $\mathrm{C}_{3}$ positions of indole ring. The morphology of PFIn film on carbon fibers was investigated through SEM observation, which indicated that PFIn film tightly wrapped over carbon fibers (PFIn/CF). Electrochemical results indicated that PFIn/CF electrode showed a remarkable specific capacitance of $637 \mathrm{~F} \mathrm{~g}^{-1}$ at $20 \mathrm{~A} \mathrm{~g}^{-1}$. The energy density reached about $42 \mathrm{Wh} \mathrm{kg}^{-1}$ at a high power density of $21 \mathrm{~kW} \mathrm{~kg}^{-1}$. Furthermore, PFIn/CF still maintained about $74.1 \%$ of initial specific capacitance and $100 \%$ coulombic efficiency after 1000 cycles. These results revealed that PFIn/CF was a promising electrode material for the flexible supercapacitors application.
\end{abstract}

Keywords: Surpercapacitors; Conducting polymer; Poly(7-formylindole); Carbon fibers; Capacitance performance

\section{$\underline{\text { FULL TEXT }}$}

(C) 2017 The Authors. Published by ESG (www.electrochemsci.org). This article is an open access article distributed under the terms and conditions of the Creative Commons Attribution license (http://creativecommons.org/licenses/by/4.0/). 